\title{
The Future Design Process for Cultural Silver Jewelry Around the Communities of the Si Satchanalai Historical Park, Sukhothai
}

\author{
Wilailak Choochuy ${ }^{1}$, Jirawat Phirasant $^{1} \&$ Witiya Pittungnapoo ${ }^{1}$ \\ ${ }^{1}$ Naresuan University, Phitsanulok, Thailand \\ Correspondence: Wilailak Choochuy, Naresuan University, Thailand. E-mail: aj.tangmodesign@gmail.com
}

Received: March 18, 2018

Accepted: April 4, 2018

Online Published: April 18, 2018

doi:10.5539/ach.v10n2p27

URL: http://dx.doi.org/10.5539/ach.v10n2p27

\begin{abstract}
The purpose of this research was threefold. The first objective was to analyze the community context and the existing design process for cultural silver jewelry around the communities of the Si Satchanalai Historical Park, Sukhothai Province. This was followed by the development of a future design process. Finally, an evaluation on the level of satisfaction with the new design process was conducted. The research instruments included an in-depth interview, a non-participatory observation, the focus group discussion, questionnaire, seminars and displays. The procedure of developing the future design process for cultural silver jewelry included: (1) finding solutions for problems, (2) creating new design concepts, (3) sketching, and (4) prototyping. The future new design process resulted in reducing the production costs. Evaluation of the future design process also involved several aspects: the features, the concept, and the prototyping. The findings confirmed the highest level of satisfaction on the silver jewelry as rated by the community sages for the Devious Collection at 95 per cent.
\end{abstract}

Keywords: future, design, process, cultural, silver, jewelry, communities, si satchanalai, sukhothai

\section{Introduction}

Si Satchanalai Historical Park is one of the prominent historical parks (out of 10 historical parks) in Thailand. Its appearance shows appealing and unique integrating elements of Thai ancient culture and architecture. In 1953, the Si Satchanalai Park was fully restored by the Fine Arts Department of Thailand and later declared as a World Heritage Site by the UNESCO together with the Sukhothai Historical Park. Within the vicinity of Si Satchanalai Historical Park, the silver jewelry production is prominent in two sub-districts, namely, Si Satchanalai and Tehachapi. Neither of them, however, displays a similarity in their conventional silver jewelry production which was passed on from their ancestors.

As a community product, silver jewelry or a fineness, aesthetic, and value handicraft available in the market varies in style, design technique and production process - characterized by the unique community's wisdom being passed on from older generations. It was evident that people learned to make use of silver for as long as that of gold. For Thailand, the silver jewelry production can be traced back to the Sukhothai period in which the local handicraft was made for domestic purposes and later were widely spread among the local communities. Its local production process used by farmers initially relied mainly on the simple tools that were available locally (Thosaphorn, 2008, pp. 2-3).

Silver jewelry made by the communities around the Si Satchanalai Historical Park initially began by replicating the Sukhothai antique gold jewelry, and using pure silver beads instead of gold. The patterns were created and based on the ancient ornaments and parts of paintings and sculptures in the Sukhothai period. The focus on silver jewelry production was widely acclaimed for its beautiful patterns and unique value thereby differentiating it from other types of silver jewelry. Silver jewelry is thus regarded as a precious ornament made by Thai wisdom to be promoted and conserved for the next generations. Such acquired knowledge can be learned and inherited as part of the invaluable cultural heritage around the communities of Si Satchanalai Historical Park in Sukhothai province. Although silver jewelry production became the income generator, creating harmony and prosperity amongst the family system in the Si Satchanalai Historical Park communities, it can be seen that the overall situation in the present is not much different from the past whereby the local people failed to develop the distinct attribute for silver jewelry products.

To provide a clear overview depicting different pictures of handicraft features and the management of silvery jewelry products of the Si Satchanalai Historical Park communities, the author is interested in developing the 
future design process that can be applicable to the future silver jewelry designing. The development of silver jewelry future design process can benefit the silver jewelry production of every community in Thailand. Moreover, this can improve the existing silvery jewelry design process and its modern features which is currently being practiced. The findings will provide useful information for the Ministry of Industry, the Ministry of Trade, and other agencies in their promotion and development of silver jewelry production and distribution. Moreover, all levels of education will benefit from the study of local handicrafts through this research.

The research purpose is to develop the future design process of cultural silver jewelry for communities surrounding the Si Satchanalai Historical Park in Sukhothai province. The research includes a full detailed investigation of the design process in each community and the collected information to be used in developing the future design process of silver jewelry products within the communities in accordance with the international standards. This will help to strengthen and enhance the communities through the provision of knowledge and idea for future problem-solving within the communities, society and the country as a whole.

\section{Research Purposes}

1) To analyze the community context and the existing production process for cultural silver jewelry around the communities of Si Satchanalai Historical Park, Sukhothai province.

2) To develop the future design process for cultural silver jewelry around these communities.

3) To evaluate the future design process for cultural silver jewelry around these communities.

\section{Research Methodology}

An adopted mixed methods research involved an in-depth analysis of historical survey of the target areas by using available literature documents and narratives. A survey was used to collect relevant data and the sample of the target areas. Within the sample size, the respondents were those willing to participate in the survey to explore the knowledge within the community context. The qualitative research was applied through an in-depth interview together with the non-participatory observation. The research and development were conducted through the focus group discussion, seminars and displays. The quantitative research was applied by asking questions. The procedures were made up of 5 stages as below.

\subsection{Investigation of the Community Context and the Silver Jewelry Design Process of the Community}

An investigation was conducted on the community context and the silver jewelry design process of the community by collecting data from the experts, folk artists, group/community leaders, academics and community representatives. The collected data was sorted and categorized in sequential orders, starting from the design concept, prototyping, quality audit, marketing test, production, and distribution.

\subsection{Construction of the Future Design Process and the Evaluation Criteria for Cultural Silver Jewelry}

An analysis on the collected data and information derived from the structured questionnaire and the interview was carried out. The future design process concept of cultural products as suggested by Sarah (2013) covered four (4) main parts: (1) circular products, (2) product background, (3) sustainable materials, and (4) public relations.

In relation to the evaluation criteria for silver jewelry, this was conducted through an in-depth review on the relevant documents, textbooks local and international research in order to determine the frequency of structured questionnaires and interviews with experts. The criteria followed the work done by Davis (1982, p. 168), and was then applied to the community product standards for silver jewelry of TISI $(2006$, p. 2$)$ in six (6) different features, namely, beauty, material, specification, colors, price, and production process. These were then integrated to the future design process concept for cultural products in four (4) aspects: (1) circular products, (2) product background, (3) sustainable materials, and (4) public relations. The evaluation criteria for future cultural silver jewelry are then formulated.

\subsection{Development of Future Cultural Silver Jewelry}

This research involved the author to collaborate and work with the designers and folk artists to design the prototypes of silver jewelry in ten (10) collections by initially providing the preliminary sketched drawing for the future cultural silver jewelry. Two communities of the research sample which had been divided into 4 groups were given the sketch drawing. After receiving the suggestions and feedbacks on the design of silver jewelry sketches given by community sages, academics, designers, and entrepreneurs, the sketch design was revised and further developed to create the prototypes. This became the focal point for the group discussion where the design was subjected to review and criticize in relation to the evaluation criteria for future cultural silver jewelry. The evaluation criteria were categorized into ten (10) different aspects which included: beauty, material, specification, colors, price, production process, circular products, product background, sustainable materials, and public 
relations. In addition, the design inspiration was perceived and motivated from the stucco pattern of Nangphraya temple and environment within the Si Satchanalai Historical Park. Figure 1 showed the stucco pattern of Nangphraya temple and the traditional design of silver jewelry in Figure 2.

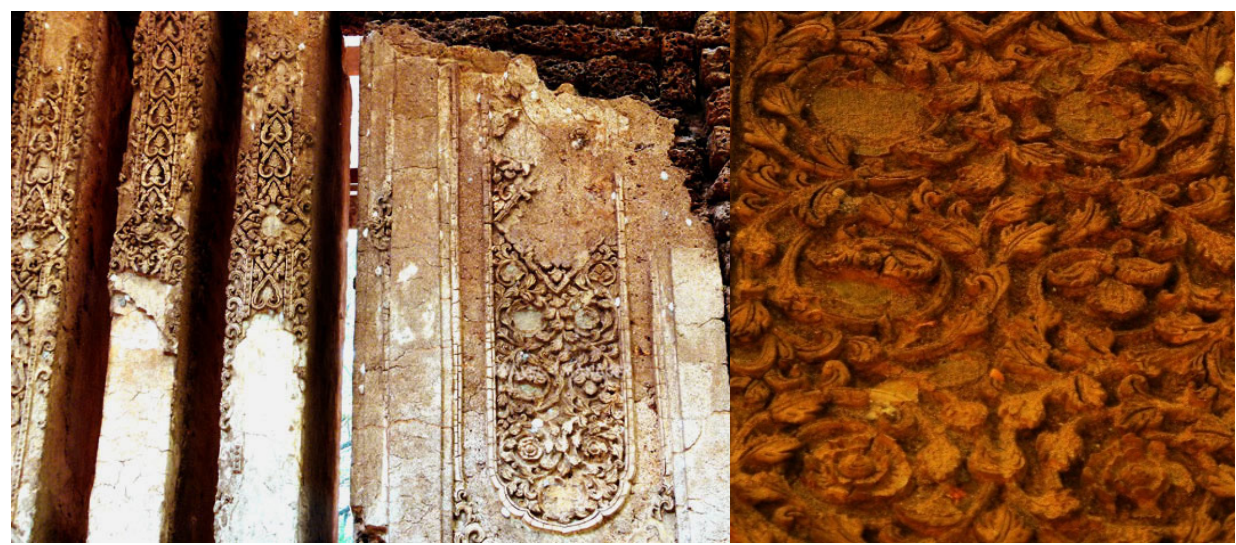

Figure 1. The stucco pattern of Nangphraya temple

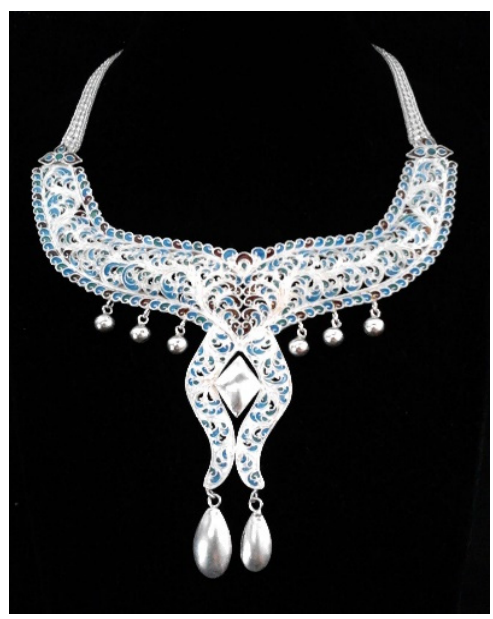

Figure 2. The traditional design of silver jewelry

From Figure 1 and Figure 2, silver jewelry from the four sample groups showed similarities in their design due to the design replication of ancient jewelry within the communities from the past. Nevertheless, the new design elements within the developed future design process were found to be easily produced, therefore reducing the production costs, and allowing the newly-design silver jewelry to be made available for the low-income class. The appearance and features of silver jewelry shifted from a conservative style to an integration of traditional and modern style. Besides, the newly-design silver jewelry was more compact and lightweight, thus allowing it to be used for various occasions than the original conservative style.

\subsection{Evaluation of the Future Design Process for Cultural Silver Jewelry}

The author organized the seminars and displays for exchanging knowledge and collecting constructive opinions and criticisms in relation to the future cultural silver jewelry with the community sages, academics, designers, and entrepreneurs. The analysis for the future design process of silver jewelry was in accordance with Rajili (2015, pp. 303-313), encompassing with seven (7) areas which include: (1) identification of scope of problems, (2) data collection, (3) solutions, (4) design concept, (5) sketching, (6) prototyping, and (7) conclusion and evaluation. The prototypes of future cultural silver jewelry were taken from the two communities which were: (1) Si Satchanalai community by Tong-Ekarat Group and Phanom Sukhothai Silver Jewelry Group, and (2) Thachai community by Lamtad Silver Antique Group and Baan Chang Add Silver Group. They were reviewed and evaluated in accordance to the evaluation criteria as mentioned in section 3.3. The ten (10) collections from the chosen two communities were presented from Figure 3 to Figure 12. 
Prototypes of future cultural silver jewelry by Tong Ekarat group (Figures 3 and 4).

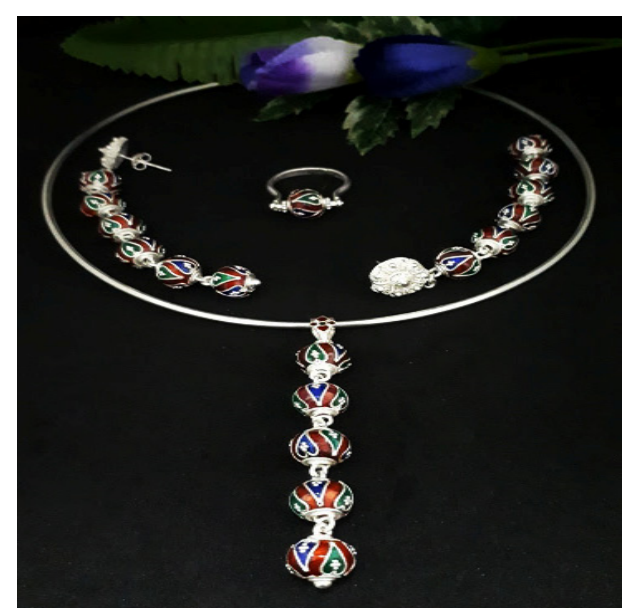

Figure 3. Pretty of Beads Collection

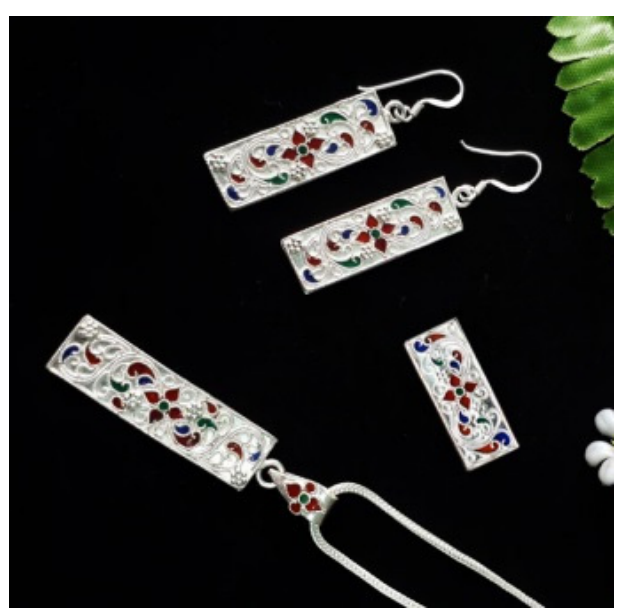

Figure 4. Curlers of Si-Sat Collection

Prototypes of future cultural silver jewelry by Phanom Sukhothai Silver Jewelry Group (Figures 5 and 6).

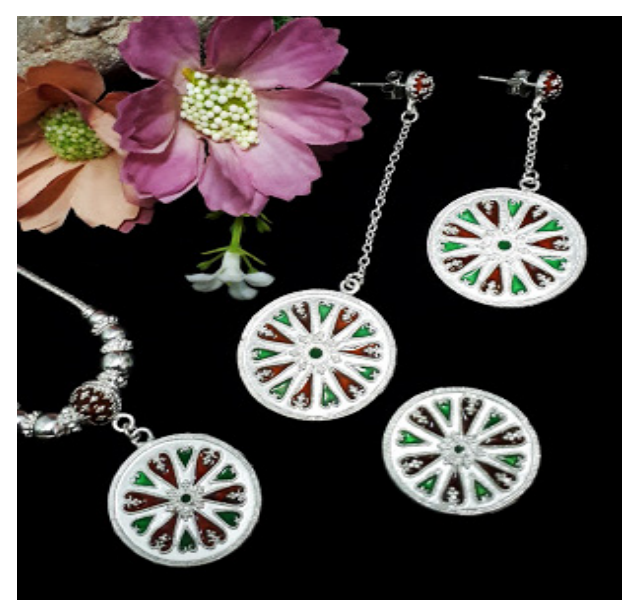

Figure 5. Circle Collection

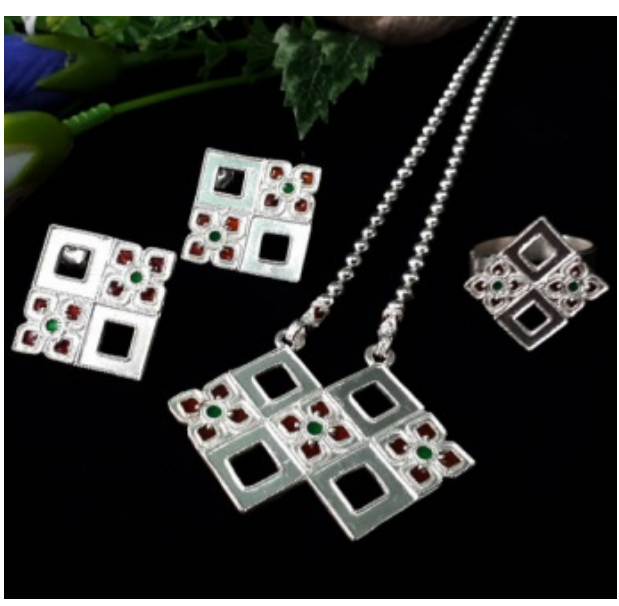

Figure 6. Square Collection

Prototypes of future cultural silver jewelry by Lamtad Silver Antique Group (Figures 7 and 8).

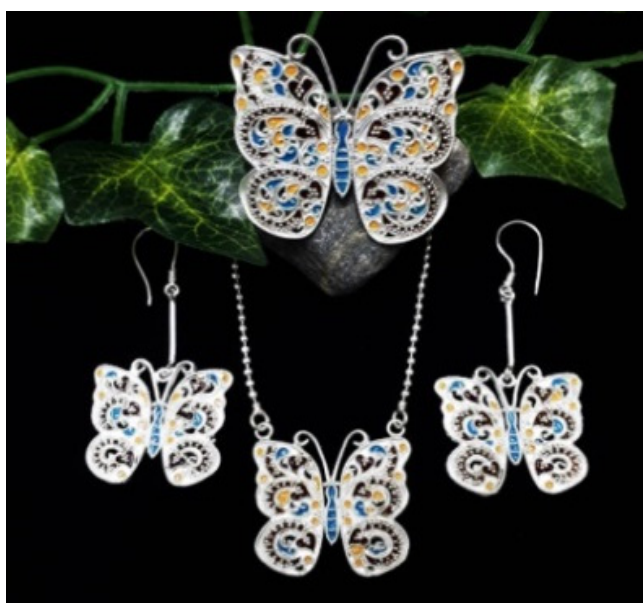

Figure 7. Butterfly Collection

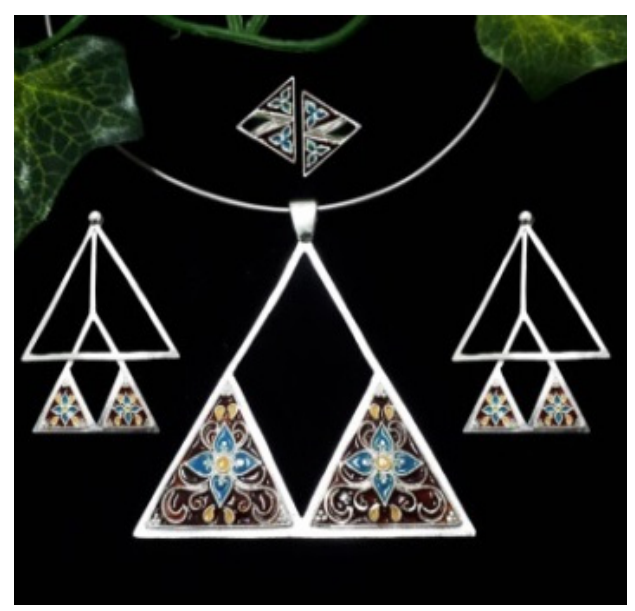

Figure 8 . The secret of flower Collection 
Prototypes of future cultural silver jewelry by Baan Chang Add Silver Group (Figures 9, 10, 11 and 12).

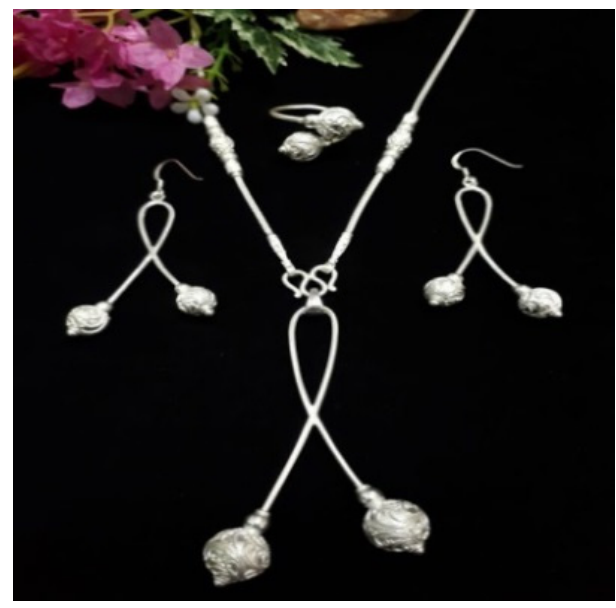

Figure 9. Togetherness Collection

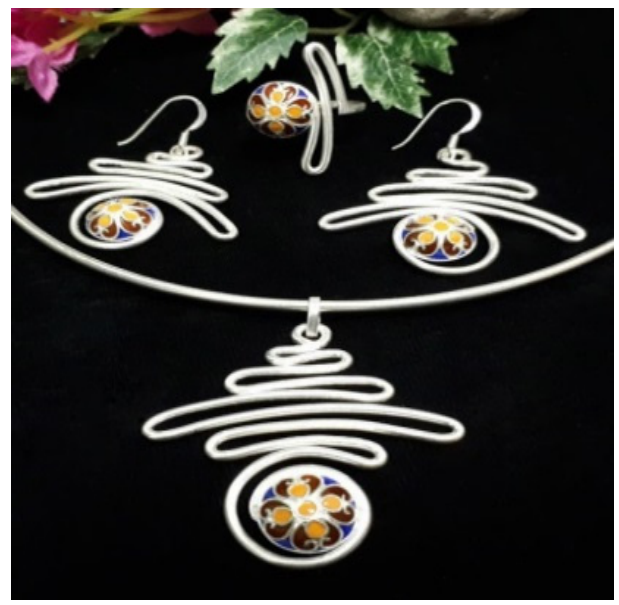

Figure 11. Devious Collection

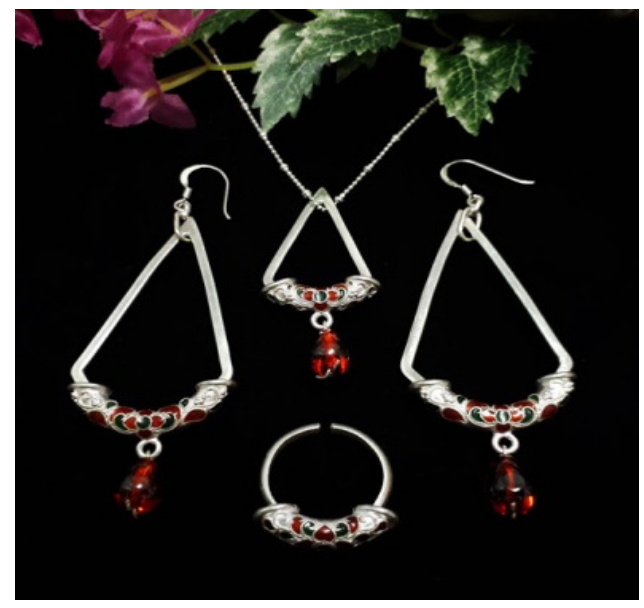

Figure 10. Blooming Collection

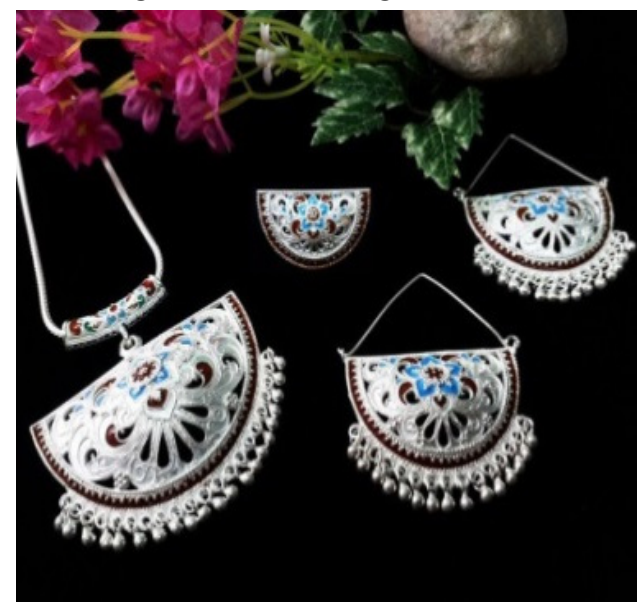

Figure 12. Lotus Collection

From section 3.2 to section 3.4, the population sample group or the experts being mentioned was individuals who were involved in designing the future cultural silver jewelry of the communities around Si Satchanalai Historical Park, Sukhothai province. A purposive sampling method was applied to obtain and select eight community sages, five academics, three designers, and four entrepreneurs from the population the sample group.

\subsection{Conclusion, Discussion and Recommendations}

1) Investigation of the primary data source: A full-detailed documentary study was conducted and illustrating the author's concept and direct experiences deduced from the technical articles, textbooks, local and international researches, dissertation for master and doctoral degrees, electronic media, academic journals, and databases of various institutes.

2) Investigation of the secondary data source: The study of biographies on the handicraft group leaders, work manuals, annual reports of the communities and research related agencies was carried out.

\subsubsection{Research Instruments}

Research instruments included an in-depth interview form, a non-participatory observation form, a semi-seminar questionnaire, an evaluation form for future cultural silver jewelry design criteria, and an evaluation form for future cultural silver jewelry design process.

\subsubsection{Data Collection}

The author collected both primary and secondary data by means of an in-depth interview, non-participatory observation, questionnaire, focus group discussion, seminar and displays. 


\subsubsection{Data Analysis}

1) Data Analysis from the technical documents: covering several related topics such as culture, community and silver jewelry design.

2) Data Analysis of the field data: preliminary analyzing the collected data from the interviews, notes of key issues, picture recording and interview-sound recording.

3) Data Analysis from the focus group discussion, notes of key issues during the focus group discussion and sound recording to prevent any confusion or possibly fading memories in the future.

4) Data Analysis on criteria evaluation for silver jewelry and the future design process for cultural silver jewelry of the communities around the Si Satchanalai Historical Park: Statistical tools were utilized to obtain the mean value, percentage, and standard deviation.

\subsubsection{Research Result}

The findings showed and confirmed the existing relationship between the degree of satisfaction of the future design process for cultural silver jewelry and the studied communities. The highest average level of satisfaction was reported by the community sages, academics, designers and entrepreneurs at the cultural silver jewelry of Baan Chang Add Silver Group. Table 1 showed the evaluation results on the satisfaction level around the communities of the Si Satchanalai Historical Park.

Table 1. The evaluation results on the satisfaction level around the communities of the Si Satchanalai Historical Park

\begin{tabular}{lcc}
\hline The population sample group & M & SD \\
\hline Community sages working on the Devious Collection & 4.81 & 0.35 \\
Academics working on the Blooming Collection & 4.72 & 0.49 \\
Designers working on the Devious Collection & 4.62 & 0.50 \\
Entrepreneurs working on the Lotus Collection & 4.79 & 0.30 \\
\hline
\end{tabular}

Note. $\mathrm{M}=$ mean value; $\mathrm{SD}=$ standard deviation; satisfaction level is in range of 1(lowest) to 5(highest).

\section{Discussion}

\subsection{Investigation of the Community Context}

Based on the field data collection and documentary study, the findings showed that the Si Satchanalai community by Tong Ekarat Group and Phanom Sukhothai Silver Group, and the Thachai community by Lamtad Silver Antique Group and Baan Chang Add Silver Group shared a similar silver jewelry design processes which can be categorized into five (5) aspects: (1) the design concept, (2) prototyping, (3) quality audit, (4) market testing, and (5) production and distribution. This was in line with the earlier work done by Tuernjai Baobang who initiated and transferred the knowledge about the production of Si Satchanalai silver jewelry in the community for over 20 years. The design process of the community of Si Satchanalai silver jewelry was described earlier as being a design replication of an antique gold jewelry by the mastering artisan. In general, after the design concept was derived from the sketch which was based on their own understanding, the artisan would proceed with prototyping by the process of forming, pressing, patterning, design perforation, and enameling. This became a lengthy process and required high skills of the artisan since Si Satchanalai silver jewelry design is quite unique with distinct detailed patterns of Si Satchanalai thereby requiring meticulousness, mastery and effort from the artisan. Enameling would also require skills, calmness and creativity in choosing different color pairs. This was followed by the quality audit of the work piece such as the fineness of structure, patterning and enameling. This is the final step before identifying the code and weight of the silver jewelry. The market testing would require the study of consumer behavior, sales summary, and feedbacks for further revision of production and distribution.

\subsection{Criteria for Future Design of Silver Jewelry Designing}

In this research, the author formulated the evaluation criteria for the future design of cultural silver jewelry to include ten (10) aspects: beauty, materials, specification, colors, price, production process, circular products, product background, sustainable materials, and public relations. The evaluation criteria were rated by the experts with a highest propriety level as a guideline for the quality and standards improvement of silver jewelry amongst the production groups. The evaluation criteria also confirmed the desirable properties of jewelry design as suggested by Wannarat (1983, p. 9) that the good jewelry features should encompass and integrate the 
design-material relationship, beauty, and practicality. The jewelry usage must not be limited to one way, but to be modified in various ways as appropriate and suitable. A simple design should be adopted for ease of clutching the garments, but it should be confidentially used without causing any harm to the users. The market price should not be too costly or expensive. The jewelry should enhance the users' character, charm, and pride. It should be easy to clean since the materials used were durable, resistant to environmental conditions, and not easily altered when subjected to changing temperatures. Most importantly, the new design should be symmetrical in shape, with harmonized colors, and marked attractive point.

\subsection{Development of Design Process}

The development of future design process for cultural silver jewelry of the communities around the Si Satchanalai Historical Park involved seven (7) key aspects: (1) identification of scope of problems, (2) data collection, (3) solutions, (4) design concept, (5) sketching, (6) prototyping, and (7) conclusion and evaluation. The discussions and seminars to exchange knowledge, and the suggestions from the experts indicated that there existed a highest propriety level of the design process to be used for future development of silver jewelry. The design process could help in reducing the production cost, increasing sales, and profits. However, the design process could be subjected to future change depending on the proficiency, skills, mastery, and experience that have been cumulated over time by each artisan. According to Lawson (2006, pp. 112-123), the design process development is quite flexible since silver jewelry can differ in the design styles. For the creation of a new style of jewelry, different processes of designing and production must be sequentially processed with a main objective of satisfying the customer needs in term of the physical function. The chosen style must represent creativity at its best.

\subsection{Discussion of the Design Process Evaluation}

Based on the collected primary and secondary data from the textbooks, local and international research works, and the interviews with experts, the evaluation criteria were formulated for assessing the future design process of cultural silver jewelry of the communities around the Si Satchanalai Historical Park. The evaluation criteria covered the ten (10) aspects: situation, features, concept, design selection, prototyping, evaluation, circular products, product background, sustainable materials, and public relations.

The findings of future design process for cultural silver jewelry as rated by the resourceful individuals such as community sages, academics, designers, and entrepreneurs - all expressed their mutual opinion that the evaluation criteria could lead the silver jewelry of each group to be widely-recognized among the outsiders in the near future. Implementing evaluation criteria can allow the jewelry to be measured for its quality, advantages and disadvantages thereby leading to the new guidance for improvement of the future silver jewelry development. This could be achieved by means of circular products, product background, and sustainable materials - all of which placed an emphasis on the importance of the environment. It is indisputable that the material for every single jewelry piece is acquired from the natural-nonrenewable resources, so it is critical for jewelry production to seriously consider the environmental limitation and not to exceed it that could result in serious consequence affecting the natural ecosystem. An environmentally and friendly approach becomes a prerequisite for sustainable jewelry production and consumption to promote and support the use of environmentally and friendly materials in making jewelry pieces. In other words, the products and services must satisfy the consumers' need while optimizing the use of natural resources, reducing emissions and pollution without causing negative impact to the environment. As suggested by Laroche (2001, pp. 503-520), the global trend indicates the demand of consumers from many countries who emphasize on the products from the production process that is not harmful to the environment. Most jewelry manufacturers are aware of this and expressed their concerns. They have revised and modified their product processes while maintaining the productivity to support the future environmentally marketing trend. It is thus crucial to contemplate on designing the jewelry piece that would allow for recycling materials and parts of the jewelry and also repairing them for reuse. Messelbeck (2000, pp. 997-1002) asserted that the most effective way to reduce environmental impacts is to start with the design process by emphasizing on using environmentally friendly materials which can be recycled by means of either reinventing from the old materials or degradation process and modification.

\section{Conclusion}

- The analysis of community context and future design process for cultural silver jewelry of the communities around the Si Satchanalai Historical Park, Sukhothai province.

1) The community context and the future design process for cultural silver jewelry of the targeted communities involved two context areas: (1) the community context of Si Satchanalai, and Thachai communities of Si Satchanalai District in Sukhothai province including general information about the silver jewelry and the trends of silver jewelry production; (past, present, future), and (2) the Si Satchanalai silver jewelry design 
process being examined in five (5) aspects of design concept, prototyping, quality audit, market testing, and production and distribution.

2) The future design process for cultural silver jewelry or known as the evaluation criteria containing ten (10) aspects, i.e. beauty, materials, specification, colors, price, production process, circular products, product background, sustainable materials, and public relations.

- Development of future design process for cultural silver jewelry of the communities around the Si Satchanalai Historical Park, Sukhothai Province.

The development of future design process for cultural silver jewelry would involve seven (7) aspects, i.e. identification of scope of problems, data collection, solutions, design concept, sketching, prototyping, and conclusion and evaluation.

- New-element integration into the design

As the result of production process being made less complicated, this can increase the sales volume for the communities. An integration of traditional and modern jewelry style in creating the jewelry piece has made it being popular since it can be easily used, and it is suitable for every occasion.

- Evaluation of the future design process for cultural silver jewelry of the communities around the $\mathrm{Si}$ Satchanalai Historical Park, Sukhothai Province.

The evaluation of future design process for cultural silver jewelry covered 10 aspects: situation, features, concept, design selection, prototyping, evaluation, circular products, product background, sustainable materials, and public relations.

\section{Recommendations}

\subsection{Recommendation for the Utilization of the Research Result}

From the findings, it can be seen that the cultural silver jewelry design processes exhibit similarities among different production groups but differs in their styles and features of silver jewelry - depending on the artisan skills in creating such uniqueness in the jewelry pieces.

\subsection{Recommendation for Further Research}

The author recommends a future exploration on the continuation of value by developing the design process for cultural silver jewelry of the communities around the Si Satchanalai Historical Park in Sukhothai Province. This is to develop and conserve the exquisite cultural heritage which is an embedded valuable and significant wisdom and local uniqueness created by the ancestors.

An extension to the development of the future design process for cultural silver jewelry of the communities around the Si Satchanalai Historical Park is recommended so that it can be adapted for other areas in the future.

\section{Acknowledgments}

This doctoral degree research on the future design process for cultural silver jewelry around the communities of Si Satchanalai Historical Park, Sukhothai province is under the financial support of the Royal Golden Jubilee Ph.D. (RGJPHD), Thailand Research Fund, and Rajamangala University of Technology Krungthep for the year 2013. The research was successfully completed with the assistance of the thesis and the cooperation of those communities, including the help of designers and friends all of whom could not be inclusively mentioned here. The author extends sincere appreciation to all of them.

\section{References}

Davis, M. L., \& Pack, G. (1982). Mexican Jewelry. University of Texas Press. https://doi.org/10.22201/iie. 18703062e.1964.33.783

Krasley, S. (2013). 5 Ways That Today's Culture Will Impact Product Designs of the Future. Fast Company magazine. Retrieved from https://www.fastcompany.com/2682282/5-ways-that-todays-culture-will-impact -product-designs-of-the-future

Laroche, M., Bergeron, J., \& Forieo, B. G. (2001). Targeting Consumers who are Willing to Pay More for Environmentally Friendly Products. Journal of Consumer Marketing, 18(6), 503-520. https://doi.org/10. 1108/eum0000000006155

Lawson, B. (2006). How Designers Think: The Design Process Demystified. Routledge. https://doi.org/10.4324/ 9780080454979 
Messelbeck, J., \& Sutherland, L. (2000). Applying Environmental Product Design to Biomedical Products Research. Environmental Health Perspectives, 108(6), 997-1002. https://doi.org/10.1289/ehp.00108s6997

Rajili, N. A. M., Liem, A., Olander, E., \& Warell, A. (2015). Processes, Methods and Knowledge Creation in Jewellery Design Practice. In ICoRD'15-Research into Design around Boundaries Volume 1 (pp. 303-313). Springer, New Delhi. https://doi.org/10.1007/978-81-322-2232-3_27

Thai Industrial Standards Institute. (2006). Silver Jewelry (p. 2). Ministry of Industry.

Thosaphorn, H. (2008). Investigating the Operations and Results After Being Awarded the Best 3-5 Star OTOP Products of Community and Local Product Business. Bangkok: Faculty of Industrial Education, King Mongkut's University of Technology North Bangkok.

Wannarat, Tangcharoen. (1983). Art Jewelry. Bangkok: Wiyon Art.

\section{Copyrights}

Copyright for this article is retained by the author(s), with first publication rights granted to the journal.

This is an open-access article distributed under the terms and conditions of the Creative Commons Attribution license (http://creativecommons.org/licenses/by/4.0/). 